\title{
Risk of mortality among alcohol using adult males in a population-based cohort in Kerala, India: PROFILE study
}

$$
\begin{aligned}
& \pi \\
& 0 \\
& 0 \\
& \frac{1}{4} \\
& \frac{1}{\pi}
\end{aligned}
$$

\section{Krishnapillai Vijayakumar, Rekha Rachel Philip', Shrinivasa Basavegowdanadoddi Marinaik², Pratheeksha Giridharan ${ }^{3}$, Sairu Philip ${ }^{4}$, Biju George ${ }^{5}$}

Department of Community Medicine, SMCSI Medical College, Karakonam, ${ }^{1}$ Department of Community Medicine, Amrita Institute of Medical Sciences, Kochi, Kerala, ${ }^{2}$ Department of Community Medicine, J.S.S. Medical College, Mysore, Karnataka, ${ }^{3}$ Department of Community Medicine, Govt. Medical College, Thiruvananthapuram, ${ }^{4}$ Department of Community Medicine, Govt. Medical College, Kozhikode, ${ }^{5}$ Department of Community Medicine, Govt. T.D. Medical College, Alappuzha, India

Address for the Correspondence: Dr. Rekha Rachel Philip, Department of Community Medicine, Amrita Institute of Medical Sciences, Kochi - 682 031, Kerala, India. E-mail: rekharachel@gmail.com

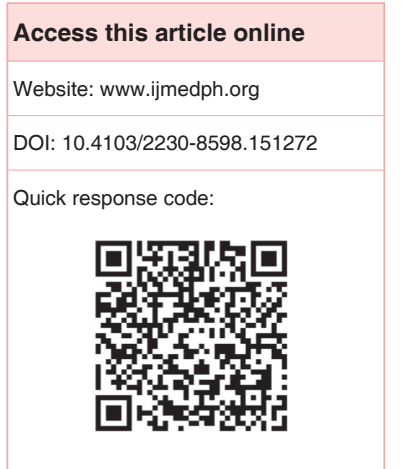

\begin{abstract}
Context: Information on the pattern of mortality among alcohol users is important for advocacy and planning. The proportion of deaths attributed to alcohol is often underestimated. Aim: We determined the risk of mortality among alcohol using adult males compared with adult male nonalcohol users. Settings and Design: Cohort study was conducted in the population registry of lifestyle diseases cohort in a rural block in Kerala, India. Materials and Methods: During 2002-2007, trained field workers conducted interviews, and underlying cause of death was coded by local physicians trained in verbal autopsy. Statistical Analysis: Risk ratios of death among men using alcohol and not using alcohol were calculated. Risk ratio of alcohol for various causes of mortality across various age groups was also determined. Log-rank test was done to compare the mortality of adult men using and not using alcohol. Results: Risk ratios of all-cause mortality in alcoholic men were $1.87(1.45,2.4)$ in 20-44 age group, $1.3(1.07,1.57)$ for $45-59$ age group. Relative risks of alcohol use status for coronary heart disease mortality were $2.91(1.67,5.05)$ among 20-44 years and $1.49(1.09,2.03)$ among $45-59$ years. Conclusion: Young and middle-aged male alcohol users (20-59 years) showed significantly increased risk ratio of death. Alcohol users have a higher risk of coronary artery disease mortality and mortality from injuries. The results support a restrictive alcohol policy and screening for coronary artery disease in men using alcohol seeking care in treatment facilities.
\end{abstract}

Key words: Kerala, Alcohol mortality, coronary mortality

\section{INTRODUCTION}

Alcohol ranks third as the leading risk factor for premature deaths and disabilities in the world. About $9 \%$ of deaths in the age group of 15 and 29 years are due to alcohol related causes. ${ }^{[1]}$ The consumption of alcohol is high in the South Indian state of Kerala, being twice as that of the national average. About $40 \%$ of men in the state are alcohol users. ${ }^{[2]}$ Information on alcohol mortality is important for advocacy for alcohol control measures in the state. However, there has been no convincing evidence from Kerala for alcohol attributable mortality.

The relationship between alcohol and mortality has been depicted to be a combination of beneficial and harmful effects. ${ }^{[3-6]}$ If low alcohol intake is inversely related to coronary heart disease, there is an increased risk of certain cancers, cirrhosis, and death from accidents from high alcohol consumption. ${ }^{[7]}$ The proportion of deaths attributable to alcohol is $1.7 \%$. This figure is likely to be an underestimation as alcohol is seldom reported as the underlying cause of death. ${ }^{[8]}$ Alcohol leads to a spectrum of disorders ranging from obesity, suicide to sudden unexpected death in alcohol misuse. ${ }^{[9]} 60 \%$ of all homicides, $45 \%$ of all deaths in automobile accidents, $40 \%$ deaths due to accidental falls, $30 \%$ of suicides and an equal proportion of all accidental drowning has been attributed to alcohol. ${ }^{[7]}$ To add to the evidence for alcohol-related health issues in Kerala and plan effective intervention strategies for alcohol control, we used the data of the population registry of lifestyle diseases (PROLIFE) cohort to determine the risk of mortality in adult male alcohol users compared with adult male nonalcohol users. 


\section{MATERIALS AND METHODS}

Details of the PROLIFE study, assignment of the underlying causes of death, statistical methods and preliminary results for various diseases and risk factors are available elsewhere..$^{[10]}$ Briefly PROLIFE is a prospective cohort study launched on $1^{\text {st }}$ July 2002 on close to 1,61,942 participants residing in Varkala rural development block in Trivandrum district of the South Indian state, Kerala. Data have been collected on events including death in the cohort till $31^{\text {st }}$ December 2007. Follow-up has been achieved for more than $80 \%$ of the cohort. ${ }^{[10]}$ Information about each participant's educational attainment (schooling in a number of years), socio economic status and age was obtained from the investigator administered questionnaire. Every home in which a death had been recorded was visited by nonmedical field surveyors to obtain information about the cause of death, occupation, education and alcohol use. An enhanced form of verbal autopsy known as a routine, reliable, representative, re sampled household investigation of mortality with medical evaluation (RHIME) was used to seek the underlying cause of each death. The RHIME method is a structured investigation of events before death, including a written report. The report was assigned to two specially trained local physicians who were medical graduates. They independently and anonymously assigned codes to causes of death using guidelines for the major causes. If the two physicians disagreed on the assigned three digit code from the international classification of diseases, $10^{\text {th }}$ Revision (ICD-10), a senior physician adjudicated. The senior physician was the professor of Community Medicine who was trained in verbal autopsy.

The deaths in this study were of all men aged 20 years and above in the PROLIFE cohort who had died between July 2002 and December 31, 2007 and whose causes of death were eventually assigned to ICD-10 codes. The interviewers who were known to the community were trained to collect information about the causes from any close associate or relative of the deceased individuals.

\section{Statistical analysis}

We calculated age-specific incidence rate of death in adult men using alcohol and men not using alcohol in the cohort. Risk of death from coronary artery diseases, cancer and injuries were estimated. We also did a log-rank test to find out any significant difference in survival among the two groups. All analysis was performed using SPSS version 16 (Chicago Il, USA).

\section{Ethics statement}

Ethical approval for PROLIFE study was obtained from Institutional Ethics Committee of Health Action by People Trivandrum, Kerala.

\section{RESULTS}

Table 1 provides a description of the study cohort with regard to sociodemographic variables such as age, income and education. Age was stratified into three; young (22-44 years), middle age (45-59 years) and elderly (60 years and above). While the highest proportion of alcohol users was found in the middle age $(39.5 \%)$, more than half of the alcohol users $(58.6 \%)$ were young. The prevalence of alcoholism was higher among men belonging to lower socio-economic status (36.4\%) and with low educational status (32.8\%).

Of the 1859 deaths in men aged 20 years or older, 515 were among men using alcohol. The overall incidence proportion of death among alcohol users was $4.8 \%$; varying from $1.77 \%$ in young age to $17.38 \%$ in the elderly. In nonalcohol users, it was $5.79 \%$. Risk ratio for mortality was $0.84(95 \%$ CI $0.76,0.93)$ for an alcohol user. The relation between all-cause mortality and alcohol consumption, by age, shows an increased risk ratio among younger age groups. An adult male using alcohol aged between 20 and 44 years has 1.87 times more risk for all-cause mortality compared with a nonalcohol user [Table 2].

Relative risk (RR) of death due to alcohol use across socio-economic strata and education group showed no statistically significant difference. However, alcohol use was significantly protective against mortality in the second socio economic strata $(0.76[0.63,0.90])$ and for lower education (RR 0.80 [0.72, 0.89]) [Table 3].

Table 4 shows the RR for various causes of mortality due to alcohol. Risk ratio for coronary artery disease mortality was higher among the young and middle-aged [Table 4]. The risk varied from 1.67 to 5.05 for young adults and 1.09-2.03 in the middle aged. Similarly, RR of mortality due to injuries was $1.82(1.24,2.67)$ for the young and $1.86(1.07,3.23)$ for the middle aged group [Table 4]. The log-rank test showed an overall reduction in mortality risk among alcohol users when compared to nonalcohol users.

\begin{tabular}{|c|c|c|}
\hline Variable & $\begin{array}{c}\text { Alcoholics } \\
(n=10,558)(\%)\end{array}$ & $\begin{array}{l}\text { Nonalcoholics } \\
(n=23,181)(\%)\end{array}$ \\
\hline \multicolumn{3}{|l|}{ Age (years) } \\
\hline $20-44(n=19,851)(\%)$ & $6190(31.2)$ & $13,657(68.8)$ \\
\hline $45-59(n=7850)(\%)$ & $3104(39.5)$ & $4746(60.5)$ \\
\hline 60 and above $(n=6038)(\%)$ & 1260(20.9) & $4778(79.1)$ \\
\hline \multicolumn{3}{|l|}{ Socioeconomic status } \\
\hline Low $(n=14,648)(\%)$ & $5336(36.4)$ & $9312(63.6)$ \\
\hline High $(n=18,515)(\%)$ & $5772(31.2)$ & $12,743(68.8)$ \\
\hline \multicolumn{3}{|l|}{ Education } \\
\hline 12 or below $(n=29,638)(\%)$ & $9711(32.8)$ & $19,927(67.2)$ \\
\hline Degree and above $(n=3230)(\%)$ & $620(19.2)$ & $2610(80.8)$ \\
\hline
\end{tabular}

PROLIFE = Population registry of lifestyle diseases

\begin{tabular}{|c|c|c|c|}
\hline \multirow[t]{2}{*}{ Age (years) } & \multicolumn{2}{|c|}{ Fatality $n$} & \multirow[t]{2}{*}{ RR (95\% Cl) } \\
\hline & $\begin{array}{c}\text { Incidence } \\
\text { of death in } \\
\text { alcoholics (\%) }\end{array}$ & $\begin{array}{l}\text { Incidence of death } \\
\text { in nonalcoholics } \\
(\%)\end{array}$ & \\
\hline $20-44$ & $110(1.77)$ & $130(0.95)$ & $1.87(1.45,2.4)$ \\
\hline $45-59$ & $186(5.99)$ & $219(4.61)$ & $1.3(1.07,1.57)$ \\
\hline 60 and above & $219(17.38)$ & $995(20.82)$ & $0.80(0.68,0.94)$ \\
\hline
\end{tabular}




\section{DISCUSSION}

The study showed an overall reduction in mortality risk among alcohol users as compared to nonalcohol users. A similar finding has been reported from a study conducted among British men where in lifelong teetotalers had inadequately explained higher risk of mortality especially from noncardiovascular events. ${ }^{[1]}$ However, the nondrinkers in our study are a heterogeneous group comprising of both lifelong teetotalers and ex-drinkers. Hence, all-cause mortality could be higher in ex-drinkers than lifelong teetotalers. Literature says that a low level of alcohol consumption is significantly associated with reduced total mortality. ${ }^{[12]}$ The lower mortality in our study could also be due to a nondifferential under reporting of alcohol consumption. This could have led to an underestimation of an elevated RR. This tendency is well-documented in the literature. ${ }^{[13,14]}$

We observed that the incidence of death increased from $1.77 \%$ in young alcoholics to $17.38 \%$ in older alcoholics. This could be because younger alcoholics may have had shorter histories of alcohol abuse and thus lesser exposure, than groups of older alcoholics. ${ }^{[15]}$ The incidence of death was higher in young aged and middle aged alcohol users than nonalcohol users in the corresponding age category. Hence, alcohol was a risk factor for death in these two categories with a higher RR in young adults (1.87) and 1.3 in the age category 45-59 years [Table 2].

Alcoholism has been associated with a greater excess mortality in younger individuals and males. ${ }^{[16]}$ A systematic review done by White et al. in England show that increased risks of all-cause mortality can occur even in people drinking lower than recommended limits and among younger people. ${ }^{[16]}$ However, alcohol appeared to

\begin{tabular}{lcccc}
$\begin{array}{l}\text { Table 3: RR of death due to alcohol use across } \\
\text { socioeconomic strata }\end{array}$ & $\begin{array}{c}\text { Death in } \\
\text { alcohol } \\
\text { users }\end{array}$ & $\begin{array}{c}\text { Death in } \\
\text { nonalcohol } \\
\text { users }\end{array}$ & RR & $95 \%$ CI \\
\hline Variable & 77 & 127 & 0.85 & $0.64,1.12$ \\
\hline Socioeconomic status & & & & \\
1 & 161 & 409 & 0.76 & $0.63,0.90$ \\
2 & 215 & 638 & 0.90 & $0.77,1.04$ \\
3 & 48 & 148 & 0.88 & $0.64,1.21$ \\
4 & & & & \\
Education & 481 & 1233 & 0.80 & $0.72,0.89$ \\
Low & 16 & 53 & 1.27 & $0.73,2.21$ \\
High &
\end{tabular}

$\mathrm{RR}=$ Relative risk, $\mathrm{Cl}=$ Confidence interval offer significant protection against death in the elderly age group $(60+$ years). This reduction in mortality risk could be due to excess risk among those in the nondrinking categories who stopped drinking because of underlying disease.

Alcohol-related mortality has been reported to be higher among lower socioeconomic groups. ${ }^{[17,18]}$ However Edwards et al., found that the alcohol-related mortality was greater for more privileged alcoholics. ${ }^{[19]}$ In contrast, we found that alcohol use was significantly protective against mortality in the middle economic stratum. We also could not observe any difference in the incidence of death among alcohol users and nonalcoholic users in the lowest stratum. Similar risk in the nondrinking category could be due to a higher prevalence of other risk behaviors such as smoking among these men.

Educational differences in alcohol-related mortality are especially large for men in some countries such as Hungary and the Czech Republic. ${ }^{[20]}$ However, in our study we did not observe this difference. Alcohol was protective against mortality for alcohol using men with lower education. This could be because of higher risk exposure in nondrinking category, or it could be due to under reporting of alcohol use. In higher education category alcohol was a risk for mortality though it was not significant statistically. This could be because of the presence of other risks of mortality in the nondrinking group.

Risk ratio for coronary artery disease was higher among the young and middle-aged men using alcohol. This reduction in risk for coronary mortality with increasing age is well-supported by an earlier study. ${ }^{[5]}$ The British Regional Heart Study of middle-aged British men has shown that $70 \%$ of nondrinkers are ex-drinkers. Those ex-drinkers had high rates of doctor-diagnosed illnesses and had an increased likelihood of becoming nondrinkers. A significantly higher risk of death among alcohol using young men needs to be considered seriously. Health promoting attributes such as emotional intelligence have been proved to be useful for reducing high risk behaviors associated with adolescent and adult alcohol use. ${ }^{[21]}$ The risk for coronary artery disease mortality was more than the other causes of mortality unlike an earlier study which reported that heavier drinkers were at greater risk for death from noncardiovascular causes. ${ }^{[20]}$

Our study revealed that the alcohol was protective against cancer deaths in younger age group $(\mathrm{RR}=0.26)$. This can be explained by

\begin{tabular}{lccccc} 
Table 4: RR of alcohol for various causes of mortality & & \\
\hline Cause of death & $\begin{array}{c}\text { Number of death } \\
\text { in alcoholic }\end{array}$ & $\begin{array}{c}\text { Number of death } \\
\text { in nonalcoholics }\end{array}$ & $\begin{array}{c}\mathbf{2 0 - 4 4} \text { years } \\
\text { (RR with 95\% Cl) }\end{array}$ & $\begin{array}{c}\mathbf{4 5 - 5 9} \text { years } \\
\text { (RR with 95\% CI) }\end{array}$ & $\begin{array}{c}\text { >600 years } \\
\text { (RR with 95\% Cl) }\end{array}$ \\
\hline Cancer & 56 & 122 & $0.26(0.12,0.58)$ & $1.46(0.8,2.65)$ & $0.94(0.57,1.53)$ \\
Coronary heart disease & 193 & 403 & $2.91(1.67,5.05)$ & $1.49(1.09,2.03)$ & $1.09(0.87,1.38)$ \\
Injuries & 90 & 111 & $1.82(1.24,2.67)$ & $1.86(1.07,3.23)$ & $1.83(0.99,3.39)$ \\
Liver & 12 & 18 & $3.32(0.55,19.79)$ & $1.31(0.44,3.9)$ & $1.26(0.34,4.66)$ \\
Kidney & 18 & 42 & $1.76(0.40,7.53)$ & $1.67(0.74,3.78)$ & $0.29(0.07,1.23)$ \\
\hline
\end{tabular}

$\mathrm{RR}=$ Relative risk, $\mathrm{Cl}=$ Confidence interval 
the delayed age of onset of cancers and early death among alcoholics. Due to legal issues, many of the injuries reporting to casualties and hospitals will not add the information on alcohol association. However, our study found a higher risk of death due to injuries in both young (1.82) and middle aged (1.86) men using alcohol.

In conclusion, young and middle age men using alcohol (20-59 years) are at increased risk of death. Elderly alcohol users have a low risk of overall mortality than nonalcohol users.

Risk of death was found to be similar among drinkers and nondrinkers across various socio-economic strata. Alcohol using men have a higher risk of mortality from coronary artery disease and injuries.

Screening for coronary artery disease in alcohol users seeking care in treatment facilities might help to institute early treatment before these problems reach an irreversible stage. Our estimates clearly indicate that alcohol consumption was a risk for mortality up to the age of 59 years. Hence, we suggest regular screening for coronary artery disease in alcohol users seeking care in treatment facilities.

A major strength of our study is the large number of samples and the long duration of follow-up. This study relied on self-reported data. If there were a systematic underestimation of alcohol consumption, this might artificially shift the reported associations towards lower drinking categories and lead to underestimation of the alcohol-mortality relationship. However, studies have found self-reporting to be reliable for the general classification of drinking habits. ${ }^{[3]}$ We used a single measure of alcohol consumption at one point in time. Since intake may change over time, this could also lead to some misclassification. We could not collect information on quantity of alcohol consumption due to the difficulty of having uniform measurement.

\section{Implications}

A high taxation and regulation of physical availability of alcohol in the state of Kerala needs to be considered by the policy makers to restrict the use of alcohol. Though these measures are unpopular in the population, literature says that the increased support for such policy measures can be mediated by changes in beliefs in the harm caused by drinking. ${ }^{[2]}$ Our findings can be used as evidence for alcohol-induced harm particularly in young men in the state of Kerala where the prevalence of alcohol use is very high.

\section{ACKNOWLEDGMENT}

The authors would like to thank Dr. Ramankutty, Professor, Achuthamenon Centre for Health Science Studies, Sree Chithra Tirunal Institute for Medical Sciences and Technology, Trivandrum, Kerala and the director of Health Action by People for the encouragement and all technical support for this study. We acknowledge the help rendered by the staff at Health Action by People, Thiruvananthapuram for data collection, data entry and compilation.

\section{REFERENCES}

1. Schmidt LA, Makela P, Rehm J, Room R. Alcohol: Equity and social determinants and public health programmes. Available from: http://www. who.int/publications/2010. [Last cited on 2014 Mar 12].

2. Government of Kerala. Human Development Report 2005. Trivandrum, Kerala: State Planning Board; 2005. Available from: http://www. planningcommission.nic.in/kerala05.2005. [Last cited on 2014 Mar 12].

3. Mathers C, Ayuso-Mateos JL. Global burden of alcohol use disorders in the Year 2000: Summary of methods and data sources. Available from: http:// www.who.int/healthinfo/statistics/bod_alcohol. [Last cited on 2013 Jan 10].

4. Gaziano JM, Gaziano TA, Glynn RJ, Sesso HD, Ajani UA, Stampfer MJ, et al. Light-to-moderate alcohol consumption and mortality in the Physicians' Health Study enrollment cohort. J Am Coll Cardiol 2000;35:96-105.

5. Shaper AG, Wannamethee SG. Alcohol intake and mortality in middle aged men with diagnosed coronary heart disease. Heart 2000;83:394-9.

6. Shaper AG. Alcohol and mortality: A review of prospective studies. $\mathrm{Br} \mathrm{J}$ Addict 1990;85:837-47.

7. Alcohol: Statistics and Trends. National Institute on Drug Abuse. Available from: http://www.nida.nih.gov/alcohol. [Last cited on 2014 Mar 12].

8. Durkin A, Connolly S, O'Reilly D. Quantifying alcohol-related mortality: Should alcohol-related contributory causes of death be included? Oxf J 2010;45:374-8.

9. Templeton AH, Carter KL, Sheron N, Gallagher PJ, Verrill C. Sudden unexpected death in alcohol misuse - an unrecognized public health issue? Int J Environ Res Public Health 2009;6:3070-81.

10. Soman CR, Shahulhameed S, Ramankutty V, Vijayakumar K, Kunjukrishnapillai R, Ajayan K, et al. Cohort profile: The PROLIFE study in Kerala, India. Int J Epidemiol 2011;40:10-4.

11. Wannamethee SG, Shaper AG. Lifelong teetotallers, ex-drinkers and drinkers: Mortality and the incidence of major coronary heart disease events in middle-aged British men. Int J Epidemiol 1997;26:523-31.

12. Di Castelnuovo A, Costanzo S, Bagnardi V, Donati MB, lacoviello L, de Gaetano G. Alcohol dosing and total mortality in men and women: An updated meta-analysis of 34 prospective studies. Arch Intern Med 2006;166:2437-45.

13. Pernanen K. Validity of survey data on alcohol use. In: Gibbins RJ, editor. Research Advances in Alcohol and Drug Problems. Vol. 1. New York: Wiley; 1974.

14. Dawson DA. Measuring alcohol consumption: Limitations and prospects for improvement. Addiction 1998;93:965-8.

15. Combs-Orme T, Taylor JR, Robins LN, Holmes SJ. Differential mortality among alcoholics by sample site. Am J Public Health 1983;73:900-3.

16. White IR, Altmann DR, Nanchahal K. Alcohol consumption and mortality: Modelling risks for men and women at different ages. BMJ 2002;325:191.

17. Mäkelä P, Valkonen T, Martelin T. Contribution of deaths related to alcohol use to socioeconomic variation in mortality: Register based follow up study. BMJ 1997;315:211-6.

18. Mäkelä $P$, Paljärvi T. Do consequences of a given pattern of drinking vary by socioeconomic status? A mortality and hospitalisation follow-up for alcohol-related causes of the Finnish Drinking Habits Surveys. J Epidemiol Community Health 2008;62:728-33.

19. Edwards G, Kyle E, Nicholls P, Taylor C. Alcoholism and correlates of mortality. Implications for epidemiology. J Stud Alcohol 1978;39:1607-17.

20. Klatsky AL, Armstrong MA, Friedman GD. Alcohol and mortality. Ann Intern Med 1992;117:646-54.

21. Coelho KR. Emotional intelligence: An updated Resource for alcohol and other Drug related prevention among adolescents and adults. Depress Res Treat 2012. Available from: http://www.dx.doi.org/10.1155/2012/281019. [Last cited on 2014 Mar 13].

22. Storvoll EE, Rossow I, Rise J. Changes in attitudes towards restrictive alcohol policy measures: The mediating role of changes in beliefs. J Subst Use 2014;19:38-43.

How to cite this article: Vijayakumar K, Philip RR, Marinaik SB, Giridharan P, Philip S, George B. Risk of mortality among alcohol using adult males in a population-based cohort in Kerala, India: PROFILE study. Int J Med Public Health 2015;5:102-5.

Source of Support: Nil, Conflict of Interest: None declared. 